\title{
Comparative dose-related time-action profiles of glibenclamide and a new non-sulphonylurea drug, AG-EE 623 ZW, during euglycaemic clamp in healthy subjects
}

\author{
F.J. Ampudia-Blasco, L. Heinemann, R. Bender, A.Schmidt, T. Heise, M. Berger, A. A. R. Starke \\ Department of Nutrition and Metabolic Diseases (WHO Collaborating Centre for Diabetes), Heinrich-Heine-University Düssel- \\ dorf, Düsseldorf, Germany
}

\begin{abstract}
Summary Insulin and glucose responses to glibenclamide were studied in comparison to a novel non-sulphonylurea drug (AG) by means of the euglycaemic clamp technique. Nine fasting male subjects were connected to a Biostator and $1.75,3.5$ or $7.0 \mathrm{mg}$ glibenclamide or 1.0,2.0 or $4.0 \mathrm{mg} \mathrm{AG}$ were given and blood glucose concentrations were clamped at $10 \%$ below basal values. Glucose infusion rates were registered over $10 \mathrm{~h}$ after administration of the tablet. Maximal glucose infusion rates after glibenclamide were $40 \%$ higher compared to AG (1.75 vs $1.0 \mathrm{mg}, 3.5 \mathrm{vs} 2.0 \mathrm{mg}, 7.0$ vs $4.0 \mathrm{mg}$, respectively) and were reached after $3-3.5 \mathrm{~h}$ for all doses. After glibenclamide, area under the glucose infusion curves and maximal incremental serum insulin responses were higher by $25-40 \%$ and by $30 \%$ compared to AG when low, medium and high doses of each drug were tested. However, a linear dose relationship
\end{abstract}

was obtained for both drugs when the glucose infusion rate was plotted against the area under the insulin curve. In fact, both drugs were equipotent on a molecular weight basis. The hypoglycaemic index of both drugs (integrated glucose infusion rate divided by integrated insulin release) expressed per $\mu \mathrm{mol}$ of drug revealed a dose-dependent and parallel inverse curvilinear relation to increasing doses. This methodological approach allowed us to quantify and compare the metabolic effects of oral hypoglycaemic agents under standardised experimental conditions. [Diabetologia (1994) 37: 703-707]

Key words Glibenclamide, glyburide, sulphonylurea compounds, AG-EE $623 \mathrm{ZW}$, dose-response, time-action profiles, pharmacokinetics, glucose clamp technique.
Received: 17 November 1993

and in revised form: 28 January 1994

Corresponding author: Dr. F. Javier Ampudia-Blasco, Department of Nutrition and Metabolism, Heinrich-Heine-University Düsseldorf, P. O.Box 1010 07, D-40001 Düsseldorf, Germany

\footnotetext{
Abbreviations: AG, AG-EE $623 \mathrm{ZW} \mathrm{(((S)-(+)-2-ethoxy-4-[2-}$ ((3-methyl-1-[2-(1-piperidinyl)phenyl]-butyl)amino)-2-oxoethyl)benzoic acid); GIR, glucose infusion rate; ANOVA, analysis of variance; $A U C$, area under the curve; $\mathrm{GIR}_{\max }$, maximal glucose infusion rate; $\mathrm{T}_{\max }$, time to reach $\mathrm{GIR}_{\max }$; early $\mathrm{T}_{50}$, time to reach half-maximal glucose infusion rate before $\mathrm{GIR}_{\max }$; late $\mathrm{T}_{50}$, time to reach half-maximal glucose infusion rate after $\mathrm{GIR}_{\max }$; insulin-AUC, AUC under the serum insulin concentration curve; GIR-AUC, AUC under the GIR curve; $\mathrm{H}_{\text {index }}$, hypoglycaemic index; OHA, oral hypoglycaemic agents.
}

Despite intensive use of sulphonylurea drugs in millions of diabetic patients worldwide, there is surprisingly little information about the relationship between drug doses and their metabolic effects [1]. The ability of sulphonylureas to stimulate insulin secretion and to lower the blood glucose concentration has been demonstrated both in healthy subjects and in NIDDM patients $[2,3]$. In some previous studies, the effects of sulphonylureas were investigated either in the fasting state [4], with concomitant oral or intravenous glucose challenge [5,6] and/or with mixed meals [4, 7, 8]. More recently, glucose controlled conditions have been used to assess the metabolic effects of sulphonylureas [912]. Using different intravenous drug infusions, dosedependent effects of glibenclamide have been studied during eu- and hyperglycaemic clamps $(+7 \mathrm{mmol} / \mathrm{l})$ in healthy subjects [1]. With this experimental design, Groop et al. [1] suggested that glyburide (and other sul- 
phonylureas) may act within a narrow range of plasma concentrations.

AG is a novel, non-sulphonylurea beta-cytotropic oral hypoglycaemic agent with a short plasma half-life $(<1 \mathrm{~h})$ [13]. Like sulphonylureas, this drug acts by closure of ATP-sensitive $\mathrm{K}^{+}$-channels in the beta cell [13]. The potency of $A G$ in vitro was two times higher as compared to glibenclamide on a molar basis [13]. A preliminary clinical study in NIDDM patients has shown that $A G$ is an effective and safe treatment which preferentially lowered postprandial blood glucose excursions [14].

In order to compare the dose-effect relationship of oral glibenclamide and AG, we used the euglycaemic clamp technique to investigate the effects of these drugs on glucose metabolism and serum insulin concentration in healthy subjects.

\section{Subjects, materials and methods}

Subjects. Nine young healthy males (age $26 \pm 5$ years, body mass index $22.9 \pm 1.4 \mathrm{~kg} \cdot \mathrm{m}^{-2}$ (means $\left.\pm \mathrm{SD}\right)$ ) participated in the study. Informed written consent was obtained following a detailed explanation of the study procedure. The study protocol was approved by the local ethical committee and was carried out according to the principles of the Declaration of Helsinki. None of the subjects was on any chronic medication during the time of the study. Throughout the study, all subjects were on a weight-maintaining diet which contained at least $200 \mathrm{~g}$ of carbohydrates daily. Additionally, they were asked to abstain from alcohol, coffee and extraordinary physical exercise for at least $12 \mathrm{~h}$ prior to each experiment.

Study protocol. The subjects arrived for the study at 09.00 hours after a 12-h overnight fast. A detailed description of the glucose clamp procedure has been given elsewhere [15]. In brief, a 17gauge PTFE catheter was inserted into an antecubital vein of the left arm for repeated blood sampling. A dorsal hand or lateral wrist vein of the same arm was cannulated retrogradely, and the hand was placed in a wooden hot box (air temperature $55^{\circ} \mathrm{C}$ ) to ensure arterialization of venous blood. This catheter was connected to a Biostator (clamp mode 9:1, Life Science Instruments, Elkhardt, Ind., USA). A third catheter was inserted into an antecubital vein of the contralateral arm for the infusion of glucose $\left(20 \%\right.$ in $\left.\mathrm{H}_{2} \mathrm{O}\right)$.

Blood glucose concentration was monitored during a $30-\mathrm{min}$ baseline period before the volunteers ingested (at $\mathrm{t}=0) 1.75,3.5$, or $7.0 \mathrm{mg}$ glibenclamide (mol.wt. 494) (Euglucon N; Hoechst $\mathrm{AG}$, Frankfurt, Germany) or 1.0,2.0, or $4.0 \mathrm{mg}$ (mol.wt. 452.59) AG (Novo-Nordisk, Bagsvaerd, Denmark) with $100 \mathrm{ml}$ tap water in randomised order on the six study days for each subject.

After initial fasting glycaemia had declined by $10 \%$, indicating the stimulation of insulin secretion by the drug, the clamp mode of the Biostator was activated and blood glucose concentrations were kept constant at this slightly subnormal level. GIRs necessary to maintain blood glucose after drug intake were registered throughout the ensuing $600 \mathrm{~min}$.

Three blood samples were obtained for the determination of glucose, insulin, glibenclamide and AG during the baseline period. Blood samples for glucose and insulin measurements were drawn at 15-min intervals between $0-150 \mathrm{~min}$ and at 30 -min intervals thereafter. Samples for estimation of plasma glibenclamide and $A G$ levels were drawn at 30 -min intervals during the entire experiment.
Analyticalmethods. Blood glucose was determined by the glucose oxidase method (Beckman glucose analyzer II, Fullerton, Calif,, USA). All blood samples were centrifuged and frozen at $-20^{\circ} \mathrm{C}$ until assayed. Serum insulin concentrations were measured by radioimmunoassay (RIA, Pharmacia, Uppsala, Sweden). Interassay and intra-assay coefficient of variation of the insulin assay were 6.5 and $3.5 \%$, respectively. Plasma glibenclamide concentrations were determined by means of HPLC coupled with ultra violet wave-detection [16]. The lower limit of detection was 5 $\mathrm{ng} / \mathrm{ml}$, however, a cut-off level was set at $15 \mathrm{ng} / \mathrm{ml}$ due to lack of specificity at this low concentration in frozen samples. Plasma AG concentrations were measured by means of a competitive enzyme immunoassay after acid pepsin digestion. Long-time imprecision ranged by $10-14 \%$. Predilution up to 16 times was possible in the range of $0.8-100 \mu \mathrm{g} / \mathrm{l}$ without deviation from linearity.

\section{Calculations and statistics}

Dose-response characteristics were assessed from GIR, insulin, glibenclamide and AG concentration profiles. Metabolic effects of the low, medium, and high glibenclamide doses were compared against the respective $A G$ doses $(1.75 \mathrm{vs} 1.0 \mathrm{mg}, 3.5 \mathrm{vs}$ $2.0 \mathrm{mg}$, and $7.0 \mathrm{vs} 4.0 \mathrm{mg}$, respectively). GIR were printed at $1-$ min intervals by the Biostator and stored in a computer for subsequent data processing [17]. The GIR profiles were described by means of unimodal gamma functions with absorption lag [18]. For non-linear curve fitting the Gaus-Newton algorithm was used: $f(t)=a\left(t-t_{0}\right)^{b} \exp \left(-c\left(t-t_{0}\right)\right), a, b, c>0$, where $t_{0}$ denoted the start of glucose infusion, $t$ was the actual time and $a, b$ and $c$ were function parameters.

Based on the fitted GIR-curves, GIR $\mathrm{max}_{\max }, \mathrm{T}_{\max }$, early $\mathrm{T}_{50}$ and late $T_{50}$ were estimated and analysed using ANOVA for repeated measurements with two within-subject factors (compound and dose). Serum insulin, plasma glibenclamide and AG profiles were analysed using models of repeated measurements with three within-subject factors (compound, dose and time). Using the univariate ANOVA approach with HuynhFeldt epsilon correction for degrees of freedom, $p$ values were calculated in order to account for serial correlation. Differences between basal blood glucose concentrations, clamp glucose levels, and basal serum insulin levels on the six study days were assessed by means of the Friedman test. The AUC was determined from original profiles using the trapezoidal formula.

Computations were performed using the SAS/STAT procedure GLM, the SAS/ETS procedure MODEL, and own programs in matrix language (SAS Institute Inc., Cary, Ind., USA). Results are given as means \pm SD. Statistical significance was assumed if $p<0.05$.

\section{Results}

Basal blood glucose concentrations, glucose clamp levels and basal serum insulin concentrations were comparable on all six study days (Table 1).

Glucose infusion rates. The decline in blood glucose after drug intake was more rapid with increasing doses of both drugs (Table 1). However, there were no differences in the time to reach the glucose clamp level when 2.0 and $4.0 \mathrm{mg} \mathrm{AG}$ were administered.

The blood glucose lowering effect of glibenclamide and $\mathrm{AG}$ resulted in clearly different dose-dependent 
Table 1. Pharmacodynamic and pharmacokinetic properties of glibenclamide and AG-EE $623 \mathrm{ZW}$ when given in three different doses in nine healthy volunteers during six euglycaemic clamp studies

\begin{tabular}{|c|c|c|c|c|c|c|c|}
\hline & \multicolumn{3}{|c|}{ Glibenclamide } & \multicolumn{4}{|c|}{ AG-EE 623 ZW } \\
\hline & $1.75 \mathrm{mg}$ & $3.5 \mathrm{mg}$ & $7.0 \mathrm{mg}$ & $1.0 \mathrm{mg}$ & $2.0 \mathrm{mg}$ & $4.0 \mathrm{mg}$ & $p$ value \\
\hline Basal blood glucose (mmol/l) & $5.0 \pm 0.3$ & $5.0 \pm 0.4$ & $5.0 \pm 0.2$ & $5.0 \pm 0.2$ & $5.1 \pm 0.4$ & $4.8 \pm 0.4$ & $0.752^{\mathrm{a}}$ \\
\hline Clamp glucose level (mmol/l) & $4.5 \pm 0.3$ & $4.4 \pm 0.3$ & $4.5 \pm 0.2$ & $4.4 \pm 0.2$ & $4.6 \pm 0.3$ & $4.3 \pm 0.3$ & $0.557^{a}$ \\
\hline Time to reach clamp level (min) & $91 \pm 29$ & $74 \pm 25$ & $61 \pm 16$ & $91 \pm 38$ & $70 \pm 29$ & $71 \pm 26$ & 0.049 \\
\hline $\mathrm{GIR}_{\max }\left(\mathrm{mg} \cdot \mathrm{min}^{-1} \cdot \mathrm{kg}^{-1}\right)$ & $2.3 \pm 1.1$ & $4.0 \pm 1.5$ & $5.4 \pm 1.6$ & $1.4 \pm 0.7$ & $2.3 \pm 0.8$ & $3.5 \pm 1.1$ & 0.0002 \\
\hline $\mathrm{T}_{\max }(\min )$ & $185 \pm 42$ & $192 \pm 54$ & $232 \pm 124$ & $195 \pm 70$ & $210 \pm 77$ & $192 \pm 74$ & 0.307 \\
\hline early $\mathrm{T}_{50}(\mathrm{~min})$ & $120 \pm 31$ & $120 \pm 38$ & $109 \pm 44$ & $99 \pm 43$ & $118 \pm 57$ & $112 \pm 45$ & 0.689 \\
\hline late $\mathrm{T}_{50}(\mathrm{~min})$ & $337 \pm 101$ & $359 \pm 51$ & $526 \pm 338$ & $470 \pm 240$ & $437 \pm 205$ & $372 \pm 107$ & 0.47 \\
\hline Basal serum insulin (pmol/l) & $26 \pm 8$ & $30 \pm 11$ & $30 \pm 15$ & $27 \pm 8$ & $34 \pm 13$ & $30 \pm 9$ & $0.267^{\mathrm{a}}$ \\
\hline Incremental peak serum insulin $(\mathrm{pmol} / \mathrm{l})$ & $68 \pm 39$ & $113 \pm 70$ & $192 \pm 151$ & $47 \pm 16$ & $81 \pm 37$ & $129 \pm 65$ & 0.001 \\
\hline Time to peak serum insulin (min) & $132 \pm 59$ & $155 \pm 53$ & $138 \pm 67$ & $143 \pm 84$ & $135 \pm 75$ & $127 \pm 70$ & 0.893 \\
\hline Peak plasma drug concentration (ng/ml) & $60 \pm 23$ & $97 \pm 43$ & $188 \pm 48$ & $21 \pm 19$ & $33 \pm 15$ & $84 \pm 40$ & \\
\hline Time to peak drug concentration (min) & $167 \pm 95$ & $167 \pm 103$ & $157 \pm 83$ & $83 \pm 51$ & $93 \pm 63$ & $107 \pm 64$ & 0.007 \\
\hline
\end{tabular}

mean $\pm \mathrm{SD} ;{ }^{\mathrm{a}}$, Friedman test; ANOVA for repeated measurements

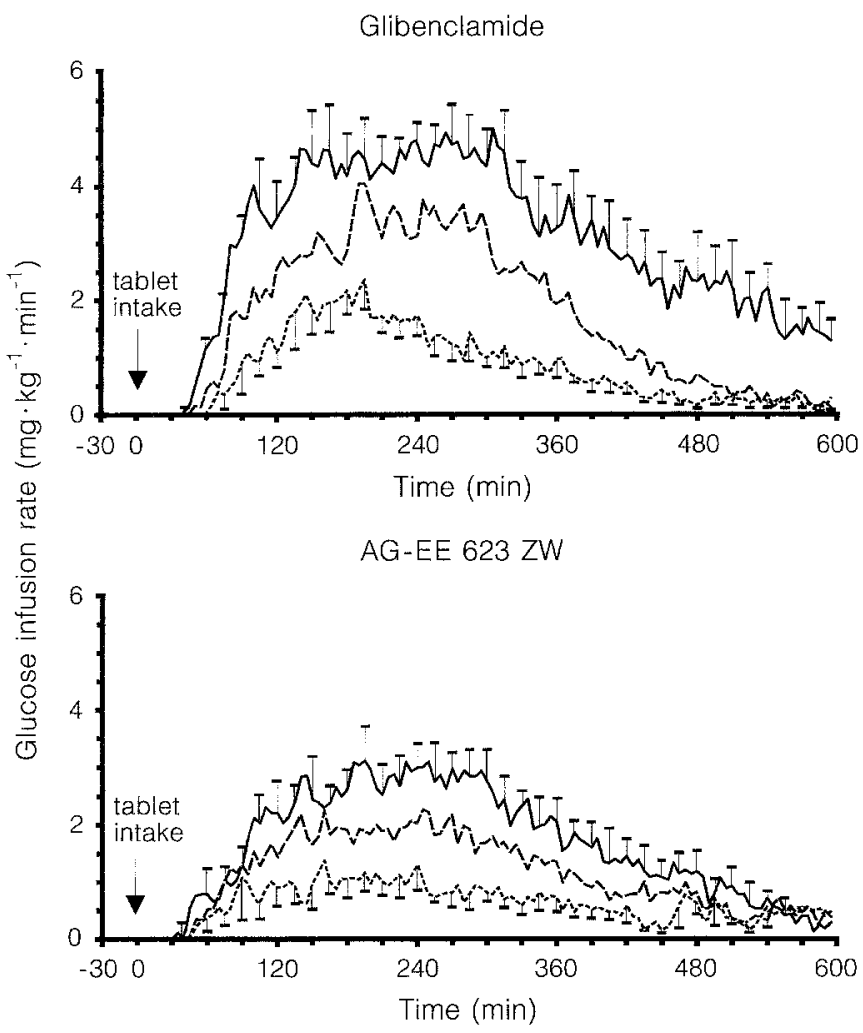

Fig. 1. Mean ( \pm SEM) of individual glucose infusion rate profiles after orally administered glibenclamide $(1.75,3.5$, and $7.0 \mathrm{mg}$ ) and $\mathrm{AG}(1.0,2.0$, and $4.0 \mathrm{mg})$ in 9 healthy subjects. Blood glucose was clamped at $10 \%$ below the fasting basal glucose values after tablet intake. High, medium and low dose of each drug are represented by continuous, broken or dotted lines, respectively

GIR-profiles with the three tested doses (Fig. 1). The maximal blood glucose lowering effect $\left(\mathrm{GIR}_{\max }\right)$ increased by a factor of 2.3 between 1.75 and $7.0 \mathrm{mg}$ glibenclamide (Table 1 ). There was a similar 2.5 -fold increase of the maximal hypoglycaemic effect registered after $\mathrm{AG}$ between 1.0 and $4.0 \mathrm{mg}$. The maximal hypoglycaemic action of AG for all doses was only
$60 \%$ of the glibenclamide effect when low, medium and high doses of both drugs were compared. However, $\mathrm{GIR}_{\text {max }}$ values obtained after 1.75 and $3.5 \mathrm{mg}$ glibenclamide were similar as compared to $\mathrm{GIR}_{\max }$ values after 2.0 and $4.0 \mathrm{mg} \mathrm{AG}$, respectively. The maximal hypoglycaemic effect $\left(\mathrm{T}_{\max }\right)$ was reached after $3-3.5 \mathrm{~h}$ and was similar with both drugs at the three evaluated doses (Table 1). There were also no differences in early $\mathrm{T}_{50}$ and late $T_{50}$ between glibenclamide and $A G$ whichever dose was used.

The AUC of the GIR-profiles - as an expression of the total metabolic effect over time -increased linearly after the three doses of each drug (Fig. 2). The AUC of the GIR-profile after 1.75 and $3.5 \mathrm{mg}$ glibenclamide was $27 \%$ and $57 \%$ of that of $7.0 \mathrm{mg}$, respectively. The total metabolic effect of AG was lower than that of glibenclamide when low, medium and high doses of both drug were compared. The AUC of the AG profiles of $1.0,2.0$ and $4.0 \mathrm{mg}$ were $76 \%, 67 \%$ and $55 \%$ of the respective AUC-values registered after 1.75, 3.5, and $7.0 \mathrm{mg}$ glibenclamide. However, AUC values obtained after 1.75 and $3.5 \mathrm{mg}$ glibenclamide were similar as compared to 2.0 and $4.0 \mathrm{mg} \mathrm{AG}$, respectively.

Serum insulin concentrations. Similar to the GIRprofiles serum insulin profiles showed a dose-dependent increase after each drug (Table 1). Mean maximal serum insulin responses increased three-fold with $7.0 \mathrm{mg}$ as compared to $1.75 \mathrm{mg}$ glibenclamide (Table 1). The maximal serum insulin responses of each dose of $\mathrm{AG}$ were about $70 \%$ of the maximal response of glibenclamide when low, medium and high doses of both drugs were compared. However, the time to reach the peak serum insulin concentration was similar for all doses of each drug.

The AUC derived from serum insulin profiles after glibenclamide and AG showed a dose-response relationship (Fig. 2). The maximal integrated insulin response was obtained by $7.0 \mathrm{mg}$ glibenclamide; 1.75 and $3.5 \mathrm{mg}$ glibenclamide reached $41 \%$ and $63 \%$ of the in- 


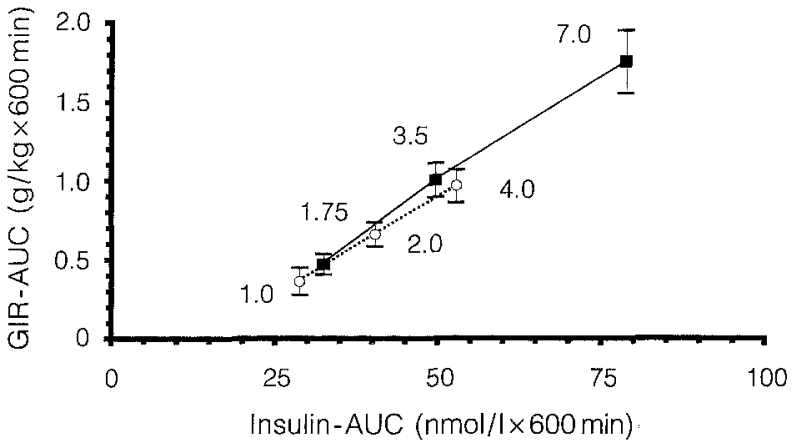

Fig. 2. AUCs obtained from GIR-curves were plotted against AUC from serum insulin concentration curves for $1.75,3.5$, $7.0 \mathrm{mg}$ glibenclamide (a) or $1.0,2.0,4.0 \mathrm{mg} \mathrm{AG}(\mathrm{O})$. These values represent the absolute amount of glucose necessary to maintain blood glucose at the clamp level after pancreatic insulin secretion was stimulated by tablet intake. Means \pm SEM are given

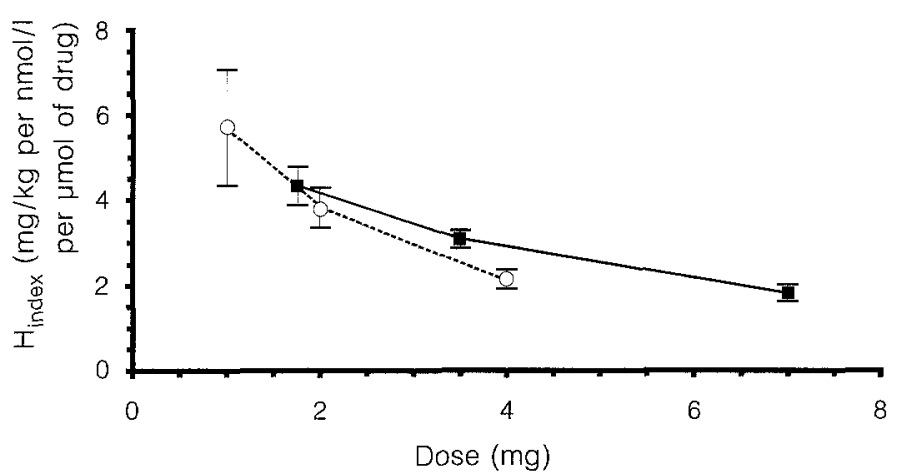

Fig. 3. $\mathrm{H}_{\text {index }}$ on a molar basis after $1.75,3.5,7.0 \mathrm{mg}$ glibenclamide (a) or 1.0,2.0,4.0 mg AG (O). $\mathrm{H}_{\text {index }}$ is expressed in $\mathrm{mg} / \mathrm{kg}$ body weight of infused glucose per nmol/l of insulin per $\mu \mathrm{mol}$ of drug

sulin-AUC after $7.0 \mathrm{mg}$ glibenclamide, respectively. The insulin-AUC of $1.0,2.0$ and $4.0 \mathrm{mg} \mathrm{AG}$ were $88 \%$, $81 \%$ and $67 \%$ as compared to the low, medium and high glibenclamide doses.

When the total metabolic effect on glucose metabolism (GIR-AUC) was plotted against the integrated serum insulin response (insulin-AUC) an almost linear dose-relationship was observed (Fig. 2). Based on the GIR-AUC and insulin-AUC values of each dose a hypoglycaemic index was obtained (GIR-AUC divided by insulin-AUC, expressed in $\mathrm{mg} / \mathrm{kg}$ of infused glucose per nmol/l of insulin per $\mu \mathrm{mol}$ of drug). As shown in Figure 3 , the $\mathrm{H}_{\text {index }}$ per $\mu \mathrm{mol}$ of administered drug decreased as an inverse curvilinear function when increasing amounts of drug were used, irrespective of the type of drug.

Plasma drug concentrations. Plasma drug concentration profiles increased dose-dependently with the three doses of glibenclamide and AG studied (Table 1). Mean maximal glibenclamide concentrations were three times higher after $7.0 \mathrm{mg}$ as compared to $1.75 \mathrm{mg}$. The maximal plasma concentration of 1.0 and $2.0 \mathrm{mg}$
AG were $25 \%$ and $39 \%$, respectively of the maximal concentration reached after $4.0 \mathrm{mg}$. Peak glibenclamide concentrations after the three doses were reached significantly later-more than $1 \mathrm{~h}$-as compared to AG.

\section{Discussion}

In the present study we have examined the dose-effect relationships of two orally administered beta-cytotropic compounds in healthy subjects under glucose controlled conditions. Glibenclamide and AG showed a clear dose-dependent increase of serum insulin levels and glucose infusion rates. Based upon the absolute weight in $\mathrm{mg}$, both tested drugs demonstrated indistinguishable metabolic effects ( $\mathrm{T}_{\max }$, GIR $\left._{\max }, \mathrm{GIR}-\mathrm{AUC}\right)$ when doses of 1.75 and 3.5 mg glibenclamide were compared with 2.0 and $4.0 \mathrm{mg} \mathrm{AG}$ (Table 1).

As with glibenclamide, we found that an increase of plasma AG concentrations preceded both the increase of serum insulin levels and the increase of GIR. Although the time to reach the maximal drug concentration level was significantly shorter after AG, metabolic effects of both drugs were recorded at similar times after administration (early $\mathrm{T}_{50}, \mathrm{~T}_{\max }$ ). With increasing drug doses the metabolic effects increased in a linear, dose-dependent manner. Although dose-dependent effects of glibenclamide on the GIR and insulin profiles were higher as related to $A G$ when low, medium and high doses of both drugs were compared, these differences disappeared when both drugs were compared on the absolute weight (mg) and molecular basis.

The $\mathrm{H}_{\text {index }}$, i.e. the integrated glucose infusion rate divided by the integrated serum insulin concentration, expressed per $\mu \mathrm{mol}$ of drug showed a dose-dependent decline with increasing doses. Beta-cytotropic agents seem to have a lower efficacy with increasing doses. In fact, as suggested by Groopet al. [1] the maximum effective oral dose of glibenclamide would be less than $10 \mathrm{mg}$.

AG was developed and designed as a drug with assumed pharmacodynamic effects of shorter duration as currently available sulphonylureas in order to cover the prandial insulin requirements due to its short plasma half-life. In our model, AG demonstrated a similar time-action profile and potency as glibenclamide in the range of tested doses. Both drugs elicited a hypoglycaemic action which extended beyond the physiological demands needed to cover prandial insulin requirements, as can be seen from $T_{\max }$ and late $T_{50}$ (approximately between $3-4 \mathrm{~h}$ and $5.5-7.5 \mathrm{~h}$, respectively). To this end, a hypoglycaemic agent with a shorter time-action profile would be more desirable.

The importance of examining the beta-cell secretory response to sulphonylurea drugs at identical glycaemic levels has already been underlined by Hosker and coworkers [12]. Insulin responses to oral hypoglycaemic agents should be studied at comparable glucose levels $[2,5]$, as has been demonstrated when the insulin re- 
sponse was investigated after a chronic treatment with sulphonylureas in NIDDM patients $[11,19]$. In these studies, the use of glucose-controlled insulin infusion systems had allowed the blood glucose to remain constant at the desired level during the experiment.

It has been shown that elevated ambient blood glucose levels increased the effect of sulphonylurea on insulin secretion [9-11, 20]. In the present study, blood glucose levels were clamped at euglycaemic levels in order to investigate only the pharmacological dose-response relationships of the drugs independently of other beta-cytotropic effects. Furthermore, it has been demonstrated that increasing levels of attained hyperglycaemia may cause a dose-dependent reduction of the plasma glipizide concentration in non-diabetic subjects due to hyperglycaemia-induced delay of intestinal absorption [21]. There is no reason to believe that this finding, also demonstrated in IDDM patients, is unique to glipizide [3].

Use of GIR values to assess the rate of glucose uptake after the administration of oral hypoglycaemic drugs is not new $[1,9,20]$. However, all of these studies were performed to investigate the influence of sulphonylurea drugs on insulin secretion $[1,9,20]$ and hepatic glucose production [9]. Eu- and hyperglycaemic clamps were performed in healthy and NIDDM patients after glibenclamide and/or glipizide were given either intravenously $[1,9]$ or by oral administration [20]. However, these studies were of shorter duration $(<4 \mathrm{~h}$ ) as compared to the present study and in neither of them were GIR profiles during euglycaemic clamps reported.

In conclusion, the methodological approach described in this study allows to quantify and compare the metabolic characteristics of different oral beta-cytotropic hypoglycaemic agents under standardised conditions. This method seems to be suitable and valid to compare time-action profiles and dose-response relationships of different hypoglycaemic agents.

Acknowledgements. The technical assistance of Ms. I.Kremer is gratefully acknowledged. The author (F. J. Ampudia Blasco) was a recipient of a grant from Fondo de Investigaciones Sanitarias (Spain, FIS 92/5051). The support from Novo-Nordisk (Bagsvaerd, Denmark) and the Peter-Klöckner-Stiftung (Duisburg, Germany) are gratefully acknowledged. Preliminary data of this study were presented in part in abstract form, during the $28^{\text {th }}$ Congress of the "Deutsche Diabetes-Gesellschaft" (Ulm, Germany, May 19.93) and at the $29^{\text {th }}$ Annual Meeting of the EASD (Istanbul,Turkey, September 1993).

\section{References}

1. Groop LC, Barzilai N, Ratheiser K et al. (1991) Dose-dependent effects of glyburide on insulin secretion and glucose uptake in humans. Diabetes Care 14: 724-727

2. Pfeifer MA, Halter JB, Porte DJ (1981) Insulin secretion in diabetes mellitus. Am J Med 70: 579-588

3. Groop LC (1992) Sulfonylureas in NIDDM. Diabetes Care 15: $737-754$
4. Sartor G, Melander A, Scherstén B, Wahlin-Boll E (1980) Serum glibenclamide in diabetic patients, and influence of food on the kinetics and effects of glibenclamide. Diabetologia 18: $17-22$

5. Pfeifer MA, Halter JB, Judzewitsch RG et al. (1984) Acute and chronic effects of sulfonylurea drugs on pancreatic islet function in man. Diabetes Care 7 [Suppl 1]: 25-34

6. Cerasi E, Efendic S, Thornqvist C, Luft R (1979) Effect of two sulphonylureas on the dose kinetics of glucose-induced insulin release in normal and diabetic subjects. Acta Endocrinol Copenh 91: 282-293

7. El-Sayed YM, Suleiman MS, Hasan MM et al. (1989) Comparison of the pharmacokinetics and pharmacodynamics of two commercial products containing glibenclamide. Int $\mathbf{J}$ Clin Pharmacol Ther Toxicol 27: 551-557

8. Gutniak M, Karlander SG, Efendic S (1987) Glyburide decreases insulin requirement, increases beta-cell response to mixed meal, and does not affect insulin sensitivity: effects of short- and long-term combined treatment in secondary failure to sulfonylurea. Diabetes Care 10: 545-554

9. Groop L, Luzi L, Melander A et al. (1987) Different effects of glyburide and glipizide on insulin secretion and hepatic glucose production in normal and NIDDM subjects. Diabetes 36: 1320-1328

10. van Haeften TW, Veneman TF, Gerich JE, van der Veen EA (1991) Influence of gliclazide on glucose-stimulated insulin release in man. Metabolism 40: 751-755

11. Shapiro ET, Van Cauter E, Tillil Het al. (1989) Glyburide enhances the responsiveness of the beta-cell to glucose but does not correct the abnormal patterns of insulin secretion in non insulin-dependent diabetes mellitus. J Clin Endocrinol Metab 69:571-576

12. Hosker JP, Rudenski AS, Burnett MA, Matthews DR, Turner RC (1989) Similar reduction of first- and second-phase B-cell responses at three different glucose levels in type II diabetes and the effect of gliclazide therapy. Metabolism 38: $767-772$

13. Frokjaer-Jensen J, Kofod H, Godtfredsen SE (1992) Mechanism of action of AG-EE $623 \mathrm{ZW}$. A novel insulinotropic agent. Diabetologia 35 [Suppl 1]: A116 (Abstract)

14. Wolffenbuttel BHR, Nijst L, Sels JP, Menheere P, Muller PG, Nieuwenhuijzen Kruseman AC (1992) Metabolic effects of a new oral hypoglycaemic agent, AG-EE $623 \mathrm{ZW}$, in sulphonylurea (SU) treated type 2 diabetic patients. Diabetologia 35 [Suppl 1]: A200 (Abstract)

15. Starke AA, Heinemann L, Hohmann A, Berger M (1989) The action profiles of human NPH insulin preparations. Diabetic Med 6: 239-244

16. Rogers HJ, Spector RG, Morrison PJ, Bradbrook ID (1982) Pharmacokinetics of intravenous glibenclamide investigated by a high performance liquid chromatographic assay. Diabetologia $23: 37-40$

17. Heinemann L, Kamper K, Kunze W (1992) Data transfer from Biostator. Diabetes Care 15:718-719

18. Weiss M(1983) Use of gamma distributed residence times in pharmacokinetics. Eur J Clin Pharmacol 25: 695-702

19. Hosker JP, Burnett MA, Davies EG, Harris EA, Turner RC (1985) Sulphonylurea therapy doubles B-cell response to glucose in type 2 diabetic patients. Diabetologia 28: 809-814

20. Groop LC, Ratheiser K, Luzi Let al. (1991) Effect of sulphonylurea on glucose-stimulated insulin secretion in healthy and non-insulin dependent diabetic subjects: a dose-response study. Acta Diabetol 28: 162-168

21. Groop LC, Luzi L, DeFronzo RA, Melander A (1989) Hyperglycaemia and absorption of sulphonylurea drugs. Lancet 2: 129-130 